$\mathbb{T}$ periodica polytechnica

\author{
Social and Management Sciences \\ $20 / 1(2012) 45+54$ \\ doi: 10.3311/pp.so.2012-1.05 \\ web: http://www.pp.bme.hu/so \\ (c) Periodica Polytechnica 2012
}

RESEARCH ARTICLE

\section{Are we evolved to live with mobiles? An evolutionary view of mobile communication}

\author{
Chih-Hui Lai / James E. Katz
}

Received 2012-01-07

\begin{abstract}
By providing ultimate explanations for human behaviors, an evolutionary perspective lends itself to understanding why and how mobile communication occupies an ever increasingly critical role in modern life. From the perspective of evolution, human behaviors - in interaction with the environment - are driven by, and can be made understandable through the pursuit of physical and social survival and reproductive success. An evolutionary perspective can yield insight into commonalities observed in mobile communication across societies and cultures. To achieve these objectives, we revisit and reanalyze existing research on mobile communication through an evolutionary lens. In the process, we demonstrate that seemingly inexplicable activities from a conventional communication perspective can be meaningfully interpreted from an evolutionary perspective. We extend the evolutionary perspective on mobile communication to examine implications for social policy and further research.
\end{abstract}

\section{Keywords}

mobile communication - social media $\cdot$ evolutionary theory . survival $\cdot$ sexual selection

\section{Chih-Hui Lai}

Department of Communication, Rutgers University, New Brunswick, New Jersey, 08901, USA

e-mail: chihhui@ rutgers.edu

\section{James E. Katz}

Department of Communication, Rutgers University, New Brunswick, New Jersey, 08901, USA

e-mail: j.k@ rutgers.edu
The widespread use of personal mobile communication technology by people in all regions, cultures, and social strata has been ascribed to human beings' innate needs to be in contact, often for its own sake rather than to transfer any information [46]. Research consistently shows that mobile communication is used not merely for task direction and information exchange but in highly social ways such as keeping up-to-date about one's social circle (e.g., perpetual contact), signaling others of one's existence, and engaging in gossip and other grooming behaviors [29], as well as monitoring of and social control over others [75]. Moreover, many invest their mobile communication devices with magical or supernatural powers or become involved in comparative prestige rankings of their mobile devices and view them as an important element of style and fashion [8]. That is, people appropriate mobile technology for their varied social positioning purposes, which though may seem non-functional from a task-oriented viewpoint, are rooted in long-standing processes of human behavioral evolution.

Here we argue that the social-evolutionary perspective can allow a deeper understanding of mobile communication behavior. It offers a more powerful and heuristic explanation for how and why people use, and invest so substantially in mobile communication. In support of this argument, we advance four sets of propositions to demonstrate that mobile communication reflects human-evolved adaptations in ancestral and modern social environments. That said, evolutionary forces operate in conjunction with environmental influences, and by themselves cannot fully explain human behavior. In fact, some evolutionary forces only manifest themselves in reaction to the environment or are profoundly affected by it. Our central claim is that an evolutionary psychology perspective can help us understand the genesis and selection of behaviors related to the use of mobile communication and social media which would otherwise seem difficult to explain from an individual-functionalist or information processing perspective. 


\section{An evolutionary perspective}

The evolutionary psychology framework abandons the core assumptions of mainstream cognitive psychology, namely that the human mind is governed by general-purpose and contentfree mechanisms. Instead, it argues that the human mind embodies "a crowded network of evolved, domain-specific programs" and "each is functionally specialized for solving a different adaptive problem that arose during hominid evolutionary history" [87, p. 52].

In the pursuit of survival and reproduction, different information-processing mechanisms have evolved to deal with functionally specific but wide-ranging problems. These include foraging (hunting, gathering), kinship, predator defense, resource competition, cooperation, aggression, parental care, dominance and status, courtship, mateship maintenance, sexual selection, sexual conflict, paternity uncertainty and sexual jealousy, signaling and communication, navigation, and habitat selection (e.g. [5, 81, 85]).

From the evolutionary perspective, the formation of social relationships serves a wide array of survival functions. The social brain hypothesis proposes that the unusually large brain of primates results from the need to cope with complex social lives (e.g., large, intensely bonded relationships) [19]. Faced with ecological forces of expanding territorial spaces and countering predatory risks, primates formed complex social groups. This change then gave rise to the demand of maintaining bonding relationships as well as coordinating with other individuals in a group. It was this demand for social skills that led to the evolution of the primates' large neocortex volume. Individuals behave in a social group to meet their own needs as well as to adjust in coordination with others to maintain group cohesion [23]. Primates learn to cope with growing ecological challenges (e.g., survival, foraging, rearing offspring) socially and cooperatively, rather than through individual trial-and-error learning efforts [24].

Along with the complex social contexts come the competitive and destabilizing forces that have the potential to destroy a group's cohesion, and even existence. Therefore, an individual primate would tend to cement relationships with a few key partners (as a coalition) to buffer against the increasing competition and pressure from others in the large group. Individuals in a coalition build relationships based on trust and commitment, which means that they will come to others as allies during conflicts [20]. But cognitive and physical constraints of primates pose limits during this networking process of building relationships with key partners. First, individual primates are cognitively constrained by the number of individuals that they can integrate into their mental social world (a cognitive constraint). Second, they are also constrained by the time that they can afford to invest in grooming with these partners (an ecological constraint) [19] Therefore, it is not surprising to see individuals embedded in a hierarchically structured network of relation- ships, with each circle of partners distinguished based on the degree of emotional closeness and frequency of communication with the ego person [39, 93].

According to the work by Dunbar and his colleagues [17], in human society, due to the cognitive limit, 150 is the approximate maximum size of social networks that an individual can have a defined personal relationship with. This type of social network, or called active networks, usually consists of the main circle of friends, relations, and acquaintances with whom an individual has regular contact (e.g., at least on an annual basis) (e.g. [77]). But in general, individuals handle their inner circles of networks (the support clique and the sympathy group), or the so-called the grooming clique, more effectively than this outer layer of networks (the active network) [21,51].

Language evolved for communication. The adaptive importance of language has been widely explored, especially in social and cooperation contexts. Belonging to a social group affords individuals the opportunity to communicate with others about the repertoire of knowledge they accumulated with respect to the physical world and the states of other individuals in the cooperating group [70]. These together constitute the advantage for both individuals and the group in competition with other species for survival. In the primate world, social grooming, a vital mechanism for building bonds, is a dyadic activity. Because social grooming almost always involves only two individuals and does not allow the operation of other activities at the same time, it is invariably time consuming. But the evolution of language has afforded humans a more efficient way of performing social grooming [18]. Language also evolved to help maintain group cohesion. Unlike monkeys and apes who seem limited in their knowledge of their networks based on direct observation, humans can use language to exchange information, keep track of other individuals in the network who are not present, advertise their own advantages as a friend, ally, or mate (or perhaps the disadvantages of potential rivals), seek advice on personal problems, and police free riders [11,20,29] .

\section{An evolutionary view of mobile communication}

A common assertion is that the way ancestral humans faced the threat to survival and reproduction is considerably different from what we deal with now in modern society. But evolutionary thinking affords us the opportunity to look at not only the adaptations humans have evolved over the course of evolution but also how these adaptive mechanisms function now. The way people communicate with and through technology should be able to reflect these adaptations. In fact, numerous attempts have been made to comprehend how and why mobile phones are prevalently used by over two-thirds of the population in the world. An evolutionary perspective can help provide insight into these questions and unify the seemingly disparate areas of inquiry concerning mobile communication. To this end, in this article, we propose a conceptual framework of mobile communication grounded in an evolutionary perspective. This frame- 
work highlights the four dimensions of mobile phones use, including mobile networks, public performance of mobile communication, inferential strategies of using mobile phones, and gender differences, which reflect the commonly discussed topical areas in research on mobile communication.

\section{Mobile grooming networks}

From an evolutionary perspective, people tend to extend their help or deliver benefits to someone who is either genetically related, or who can reciprocate at a later point in time, or who is a friend of theirs [4]. Through these processes, the helping person obtains benefits for survival and reproduction. But people have limited time, resources and physical energy. It becomes necessary that selection should favor adaptations that help people make optimal decisions about when and to whom to extend their help [4]. This speculation leads us to ask: How can people decide who will fill the slots in the limited contact niches for lending help [86]?

As evidenced in studies of making and breaking connections via mobile communication, it is evident that people selectively choose their close ties as the ones to offer and receive help. A common research finding is that mobile communication serves to maintain existing social networks, rather than creating new ties [10,43, 83]. Studies have also shown that people tend to use mobile phones as a shield against the wider surroundings to engage in the familiar circle of social relationships with close kin or friends (e.g. [28]). Specifically for the younger generation, mobile phones (text messaging) serve as a way for them to create an inner network of alliance based on trust and reciprocity [82].

Presumably, being given or reciprocated with a mobile phone number is a critical step to being included in the mobile network. Having access to people's mobile phone numbers is accorded the importance as a token of trust [56] or as the prelude to the performance of symbolic gift-giving ritual in the form of text messages that is deemed helpful to maintain existing relationships [41, 82]. In addition to the private sphere, it is observed that people also give and exchange mobile phone numbers with others in a more public way for coordination or emergency purposes [56].

Resembling a gift-giving economy, the way people reciprocate or swap mobile phone numbers and text messages represents the evolved adaptations of humans to initiate and maintain cooperation with others in society. Intriguingly, these observations seem no different than the situation of primates and modern humans forming coalitions against the ecological stress arising from the increasing size of the social group. It can thus be posited that mobile communication networks essentially resemble the grooming clique that has played a critical role in the evolution of humans (see Table 1 ).

The grooming clique enabled by mobile phones allows humans to communicate transcending physical and spatial limitations [31]. For example, mobile communication enables par- ents to coordinate and organize their life while remotely attending to their children or without even having to leave their children [16, 34, 60, 73, 76] . Parents, equipped with mobile phones, become the embodiment of "home base" beyond the physical house that provides children with instrumental and emotional resources needed in daily life [67].

Mimic primordial communication on mobiles. People tend to spend most of their informal conversation time on social topics (e.g., explicitly social activities, personal relationships, and personal likes or dislikes) [22]. In other words, people mostly use language to exchange social information. Dunbar [20] further broadly defines these conversations about social topics as gossiping, which he argues "gossip is what makes human society as we know it possible" (p.100). Not surprisingly, variants of gossip have easily been observed in mobile communication [28]. For example, Fox's [30] study found that around three quarters of her survey respondents reported gossip on their mobiles at least once a week, with about a third indulging in mobile gossip every day.

Different terms of "grooming" talk [31] and SMS [60] and phatic calls [36] speak to the social talk function of mobile phones when used within one's close networks. In addition to small talk [41] people rely on the multiplication of very brief calls to construct a telephonic presence and maintain the relationship with their social networks [46, 55]. Rettie's [74] study showed that mobile phone calls were mostly used for giving and receiving emotional social support (to be there as social company) while text messages were used for phatic communication (a low-key form of support, "think of you" messages). In sum, people use mobile phones to reinforce the existence of relationships, open communication channels, and confirm constant connection with their social contact [57,61]. Through vocal communication and even visual messages, mobile users initiate a more immediate and unalienated form of communication, that is, immediate conveyance of multimode thought, which is especially reminiscent of the way humans communicated without mediation thousands of years ago [66].

Notably, mobile grooming networks are maintained through these primordial ways of communication, which reflect evolved adaptations designed to help humans maintain cohesion within their social group. In a social group of primates, grooming is known as a token of commitment and loyalty and a way to prevent free riders because it entails individuals' time and effort spent on grooming with certain contacts at the expense of other activities [18]. Dialects (or shared language by a group) are developed with the same functions that allow people to identify others as a friend or a foe [65]. In other words, dialects evolved as adaptations for local groups to maintain their identities and to detect free riders, given that it takes time for outsiders to learn the speech style of the group. Therefore, we argue that these grooming messages communicated over mobiles indicate ways for mobile phone users to confirm their membership in their grooming network, and readily exclude non-members; hence, 
Tab. 1. An evolutionary view of mobile communication

Mobile grooming networks

Proposition 1a: Reflecting the evolved adaptations of building cooperation through reciprocity and friendship, people use mobile phones to maintain cooperation and coordination with their social networks in the form of exchanging phone numbers and text messages.

Proposition 1b: Resembling primordial ways of communication, people engage in mobile communication through phatic talk, gossip, and multiplication of short calls with others in the social group.

Proposition 1c: The primordial ways of communication over the mobile reflect adaptive mechanisms designed to build group cohesion because people need to invest time and effort in "grooming" with their social contacts to be reassured of their social existence in the social group; they also need to use language belonging to the group, which may not be understood by out-group members.

Public social interaction via mobiles

Proposition 2a: Different types of mobile phone use in public social settings require users to initiate nonverbal communication with physically co-present individuals while verbally communicating to distant others, which represent the exercise of the adaptive mind-reading ability useful to ancestral (and contemporary) humans for survival and reproduction: Mobile phone users perform different body positioning and movement with co-present individuals to divert their attention or to command their adjustments ("in sync"); for example, for reasons of physical or social safety, people may pretend to be using their mobiles.

Proposition 2b: Mobile phone users' enactment of diverse signals in public space represents the adaptive psychological mechanisms useful to ancestral humans for survival and reproduction: Different types of public social interaction via mobiles serve the function of presenting oneself with favorable images associated with fashion, status and social inclusion.

Evolved self and social inferential strategies of mobile communication
Proposition 3a: Normative perceptions of mobile phone use in public space represent humans' evolved reasoning about what is permitted, obligated and forbidden in the situation of social hierarchy; but the reasoning formed may depend on whether and how the perceiver uses the phone in public settings.

Proposition 3b: Mobile phone use represents different forms of evolved biased judgments, including spiritual practices via mobiles reflecting humans' illusion of control of spiritual and transcendental forces, optimism about gratifications sought through mobiles, and paranoid beliefs about potential harms mobiles pose to social exclusion, overreliance and loss of control.

Proposition 4a: Public performance of mobile communication reflects different sexual intentions by men and women: Men aim to attract desirable partners by displaying status in the form of sleek devices while women care about being socially competent by getting more phone calls.

Proposition 4b: Consistent with the evolved gender differences as manifested in parental investment and mating strategies, women tend to use mobile phones for social and connectivity purposes while men focus on technical and instrumental functions; the only significant exception that women are likely to use mobile phones for safety and security reasons reflects women's evolved adaptations to secure physical protection for themselves and for their offspring from humans and nonhuman predators. they may appear incomprehensible to out-group members.

\section{Public social interaction via mobiles}

We can use the social brain hypothesis to posit that mobile communication represents dyadic, sequential interaction that is the crucial characteristic of social grooming performed by primates, but with dramatically more flexibility for multitasking as well as ease of selecting a contact for "grooming" by drawing on a device's stored phonebook. People often indulge themselves in constant mobile communication with absent others in the street while overlooking the objects (e.g., people, environments) physically around them [71]. Hence, like a pair of primates engaged in social grooming each other, people on two sides of the mobile phone immerse themselves into the dyadic interaction and activity (albeit often asynchronously). Unlike primates, however, humans use mobile phones to verbally communicate with their close contact at a distance while unwittingly nonverbally communicating with the co-present individuals [45, 71]. In cer- tain situations, this nonverbal behavior is enacted to intentionally convey the message about the mobile phone user.

From an evolutionary perspective, a variety of human behaviors and their underlying psychological mechanisms represent adaptations that evolved to equip humans with different functional abilities. The research in support of the social brain hypothesis suggests that the evolution of human intellectual ability lies in the development of "mind-reading" ability, i.e., to have a mental representation of information about physical or mental states of others that are not physically present at the time [7]. By recognizing the mental state of others, primates may attempt to mislead others and undertake various forms of deceptive tactics based on varying functional purposes, including distraction (e.g., distraction by looking away from the object of interest), creating an image (e.g., creating a threatening image), manipulation of target using social tools, and deflection of third party [90].

Applied in the context of mobile communication, we can eas- 
ily observe the process of mind-negotiation occurring between co-present people in the public space. For example, mobile phone users perform different body positioning and movement with physically co-present individuals, to divert their attention or to command their adjustments in space and pace [45,71]. For the purpose of physical safety a woman would pretend to talk on the mobile phone in the public place as a way to distract potential villains' attention [45].

Signals of self-image and fashion via mobiles. An adaptive problem faced by our ancestors is how to place themselves in group living, which allows individuals to obtain resources otherwise unattainable and thereby increases better chance of survival. Hence, one's perception of how others feel about them, a notion often called self-esteem [53], becomes an adaptive capability to alert people whether their level of social inclusion is low so that they need to initiate corrective action [50]. In other words, self-esteem was designed to gauge how individuals succeed or fail to solve adaptive problems in the form of functionally distinct interpersonal relationships and guide people to pursue social relationships that are of the highest quality possible [50].

Similar to the concept of self-esteem, costly signaling theory [91, 92] also has great bearing on the evolved public performance of human behavior, especially in the strategic context. Costly signaling theory suggests that individuals often engage in patterns of behaviors as a way to convey to others useful information about themselves (underlying quality). And these behaviors are usually costly (e.g., requirement of significant amounts of economic resources, energy, risk, or time) [1]. According to the costly signaling perspective, public prosocial behavior such as philanthropy might be a conspicuous display of resources and generosity that signals the message that an individual has the ability to undertake the costs incurred or even waste money and time. In short, these philanthropic displays, as specified in social theories (e.g., gift-giving theory, symbolic capital theory), serve as a form of social competition that demonstrates the signaler's status and prestige, which may also increase the signaler's advantage in mating decisions (for a review, see [1] .

Costly signaling theory can also help explain humans' conspicuous consumption motives, which represent manifestations of different survival modules. For example, the selling point of rich foods rests with the module of caloric hoarding while the desire to follow the arbitrary fashion trends can be traced to human need to belong [78]. The mating module is also played out in different consumption choices of men and women as sexual signaling to effectively attract mates of the opposite sex [64]. For example, women would purchase facial cream to have a youthful skin while men would buy an expensive sports car to display their status.

There are pertinent applications of the concept of evolved self-esteem and costly signaling theory in public performance of mobile communication. Numerous observations found that people, adults and teenagers alike, tend to use mobile phones to convey varying signals about themselves. For example, children would use fake phones to signal the "cool" image [48]. In the early stage of diffusion, mobile phones were seen as a social status symbol of being socially connected or as a token of group affiliation [33, 54, 80, 82] or at least as a way for individuals to present themselves favorably [68]. Men intentionally display their mobile phones in front of other men as a way to distinguish themselves with their status and wealth [63]. As an aesthetic expression, mobile phones are depicted as a piece of body jewelry and as statements of fashion and lifestyle [27, 45 49,69$]$. Conceivably, fashion itself is a type of signal indicating the signaler's ability to access information and investment of time and effort in connecting to updated sources of information [62] .

\section{Evolved self and social inferential strategies of mobile com- munication}

The aforementioned explanations of public interaction through mobile phones point to the mobile phone user's intention and behavior. But for those who are physically proximate to mobile phone users, they have developed certain strategies in response to the public use of mobiles. An evolutionary theory that touches on this dimension is dominancy theory. It is known that having preferential access to resources needed for survival and reproduction poses a set of adaptive problems for those who lack the access. Hence, humans developed strategies to solve these problems, such as reasoning about social norms involving dominance hierarchies, including permissions, obligations and prohibitions, which constitute the essence of dominance theory [14]. Under this reasoning, people pay attention to social information about what is permitted, obligated or forbidden and come to naturally adopt a strategy of seeking rule violators. For example, people tend to look for who cheats in a marriage or who smokes in a smoke-free zone.

Investigations of different perceptions of mobile phone use in public space echo this claim about social reasoning and violation detection [9, 56, 84]. People have the tendency of diverting attention to find out whose mobile phone is ringing or who is on the phone in the settings where certain social norms are applied to define appropriate social behavior. Turner, Love and Howell [88], for example, found that the acceptance of public use of mobile phones varies, depending on the context and the personal experience. People tend to feel more comfortable taking phone calls when others are present and feel less annoyed by other using mobiles in locations where they themselves felt comfortable making and receiving calls.

Adaptive biased judgment via mobiles. When making a judgment under uncertain situations, humans have the predilection for being biased toward certain scenarios rather than the other. In other words, they make biased assessments toward committing one type of error over another, after weighing the cost ratio of false positive and false negative errors and settling on the one with least cost. This is what Error Management Theory (EMT) argues: human cognitive errors result from adaptive biases that 
led to survival and reproductive advantages for humans in the ancestral environment [37]. For example, men tend to overestimate women's sexual intent (where there is none) while women underestimate men's willingness to commit (where there is willingness). These biased social inferences are beneficial to humans since men are less likely to miss the reproductive opportunity while women avoid the misery that they will be abandoned by men after making investment in the relationship [37].

Another example of the evolved biased judgment as suggested by EMT is the illusion of control. Due to random patterns of reinforcement, humans develop superstitious beliefs about actions they must perform to produce the desired contingency, which results in illusion of control, a self-related bias. That is, because the cost is less when people continue the control behavior where it is in fact ineffective (false positive) than when they miss out on the chance to control events (false negative), EMT predicts that selection should have favored a bias toward making the least costly error, in this example, superstition and the illusion of control [38].

The notion of evolved biased judgment offers tenable explanations for the convergent claims about mobile technology use. It is observed that mobile phones have been integrated as part of human spiritual practices such as prayer and requests for supernatural intercession, fortune telling, and as tokens of remembrance for the deceased [45]. These spiritual manifestations of mobiles phone use epitomizes humans' evolved biased judgment about being capable of influencing the flow of events, that is, illusion of control [38]. Similarly, people who feel less socially connected to others optimistically perceive mobile phones can help them make a status statement even though it may not be as helpful as they expect [89]. There are also paranoid beliefs about the negative ramifications of mobiles that bear on social exclusivity [47]. Some argue that constant social interaction within one's closed networks connected through mobile phones might have taken place at the expense of spontaneous socialness with co-present others who share a public space and reduced feelings of social integration [27, 44, 59].

We surmise that several other psychological manifestations of mobile phone use can also be explained with EMT, extending the theorems currently developed under EMT. People unrealistically think they cannot live without mobiles (e.g., [34, 42], think they are losing control because of being reached and reach others by mobiles [52] and feel burdened with the continued need to maintain accessibility via mobiles [79]. These psychological reactions may represent adaptive mechanisms that become activated as mobile phone users face cues that correspond to the adaptive problems our ancestors faced over the course of development [4]. The fact that people perceive they rely too much on the mobile phone may be no different than the situation where our ancestors overly feared that they relied too much on a single means of resource (e.g., food) in the environment for survival and reproduction. Following the reasoning of EMT, the cost of overestimating the reliance on a single resource is lower than the cost of not worrying about this overreliance where in fact it exists. Similarly, the paranoid feeling of losing control due to the pervasive mobile personal connectedness is a lower cost error to people than failing to control the events that are controllable.

\section{Gendered mobile communication: reproductive tactics}

From an evolutionary perspective, differences in genderbased behavior originate from the recurrently different adaptive problems faced by men and women over evolutionary history, most especially in terms of mating, that is, sexual selection [3]. But in domains where men and women faced similar adaptive problems, there exists the similarities between the sexes. The social brain hypothesis holds that females and males exhibit different patterns in terms of maintaining their social networks, which can be linked to sex differences in reproductive tactics [22]. As reflected in social conversation, for example, females tend to talk more about social networking with the aim of ensuring the smooth running of the social group while males tend to focus on self-promotion in the form of a mating lek. A lek is a mating area where males aggregate into groups to advertise their qualities as potential mates to the females [18].

Gendered public performance of mobiles. Public display of behavior often comes with the motives of sexual competition among individuals pursuing different mating strategies in different mating arenas [4]. For example, it is argued that social conversation can serve as a status display for courtship purposes [64]. Griskevicius, Tybur, Sundie, Cialdini, Miller and Kenrick [35] applied costly signaling theory to explain gender difference in mating decisions as reflected in the public display of consumption and benevolent behavior. Griskevicius et al. [35] found that romantic motives were associated with men's increased spending on conspicuous purchases (a new car, watch, taking a group of friends out to dinner, a new cell phone). Nonetheless, the romantic drive did not increase men's spending on inconspicuous purchases (basic toiletries, household medication, a bedroom alarm clock, kitchen staples, household cleaning products). Similarly, for women, romantic motives increased blatant benevolence in the form of helping behavior that is social and public (e.g., helping at a homeless shelter), but not for those that are inconspicuous in nature (e.g., spending an afternoon each weekend picking up trash alone at the park).

Evolved mating tactics are practiced in the public performance of mobile communication. Lycett and Dunbar's [63] seminal work applied sexual selection theory to observe the gender difference of mobile phone use in public places. They found that men tended to display their phones when numbers of males in the group reached five or more. In other words, the increasing number of males in a group implicitly created a competitive environment in which men used the phone to demonstrate their difference from others. Moreover, this competition intensified when the ratio of males to females increased, which resulted in more proportions of men displaying their phones publicly. To some degree, men's desire to attract desirable partners is juxta- 
posed with women's desire to be socially competent. As [54] Lemish and Cohen's study found, in terms of the perception about the role of mobile phones in daily life, women tend to view mobile phones as an indicator of social status, that is, if they get fewer calls, they are less popular. In contrast, men tend to associate mobile phones with a sign of status, a stereotypically "masculine" decision.

Differentiated grooming social networks. In addition to these nonverbal aspects, the evolutionary perspective also suggests that gender difference is pronounced in the composition of social network and social talk. Within the inner circle of social networks, females and males are known to have preference for contacts of their own gender [21].

Women tend to have more female contacts and kin in their sympathy group [25], and seemingly females generally display better skills than men at tasks relating to sociality [58]. Interestingly, these findings are congruent with observations about contemporary mobile communication. For example, women are more likely to expand their social networks connected through mobile text messaging over time than men [40]. Men tend to maintain larger networks of acquaintances through voice calls while women focus on smaller yet cohesive networks of contacts through text-messaging [32].

Women tend to use mobile phones for social and interpersonal connectivity while men focus on the technical aspects of the devices and the instrumental purposes [13, 15, 73, 80, 89]. But there is an exception. Women have long faced the recurring adaptive problem of seeking physical protection for themselves and their offspring from predators, both human and nonhuman [2, 6, 26]. Evolutionary thinking thus lends itself to the explanation of women's reliance on instrumental use of mobiles for safety and security reasons but also to carry out their traditional roles of keeping the family intact [32,72,73].

\section{Conclusion}

An evolutionary perspective provides a powerful lens to understand how and why use of new-age technology is both enormously popular and also embedded in age-old ways of behavioral and psychological adaptations. This ranges from maintaining a constrained circle of social grooming ties to engaging in primordial yet technologically enhanced gossip, from public performance of mobile communication to evolved biased judgment about mobile etiquette and social impact, from men and women's different mobile contacts to their parallel purposes of using mobile phones. The perspective puts into focus recurring adaptive problems of survival, sex and mating, parenting and cooperation via phone use. Building on hypotheses from theories of evolution, our proposed evolutionary perspective of mobile communication helps provide ultimate explanations for the intense uses of mobile communication across cultures. Though mentioned at the outset, it is important to reiterate that these behaviors derive from interaction with the environment and are not in and of themselves either inevitable or autonomous.
The proposed evolutionary framework has implications for research on communication technology in general and mobiles in particular. One of them bears on the issue of social uncertainty that arises as people feel lonely and emotionally alienated despite the perpetual contact with social networks made possible by mobile phones. People may be obligated to various forms of mobile interaction without forming meaningful and emotionally loaded relationships [72]. From an evolutionary perspective, this phenomenon of social alienation is not unique to mobile phone use. In the ancestral environment, humans lived in treacherous conditions where they needed to summon help from others (true friends). But in modern society, the living environment is relatively safe and stable. Hence, it is claimed that the lack of critical assessment events in modern society leads us to feel lonely and lost because we have no way to identify those who are deeply engaged in our welfare [86]. Observations of the situation in which people exhibit varying degrees of perceived social connectedness highlight the potential of an evolutionary perspective as a framework to probe the nature and content of relationships established and maintained through mobile communication. A relevant topic following this direction would be to examine how two groups of people, who use and who do not use mobile phones, adapt the relational management and perceive relational satisfaction differently with their circles of social contacts.

Another topic pertains to the evolving meaning of "social status gauge" attributed to mobile phones or the consumption motives of mobile phones. As suggested, mobile phones become a symbol for people to display their social status albeit with generational- and gender-appropriate variations. With continuing enhancements of mobile phone features, would those who possess the older, more primitive models perceive mobile phones differently, or be perceived differently by others? This question could impinge not only on technology diffusion and marketing but also on social policy.

In fact, viewing mobile communication through the lens of evolutionary psychology has several other implications for social policy considerations. For instance, dominance theory, which we earlier drew upon to explain the normative judgment about the use of mobile phones in public places, holds that natural selection will favor strategies that help people gain and hold control over resources. But selection also favors the evolution of subordinate strategies such as deception, friendship, manipulation, and even love to sabotage the preferred access to key resources by the dominant individuals [4].The emergence of self-organizing networks made possible through mobile phones represents an example of the evolved adaptive mind-reading capacities developed by people to counteract the advantage of resources held by those in dominant positions. Similar reasoning can apply to students' surreptitious use of mobile phones in school settings to circumvent a teacher's attention. Therefore, in the process formulating policy for mobile phone use in varying contexts (e.g., education, learning, and political mobilization), 
alternative perspectives of stakeholders in different social hierarchies should be considered.

Finally, we want to emphasize that we do NOT believe that the evolutionary perspective is an infallible framework that can account for all mobile communication use. In an increasingly networked society [12], diverse media and communication modes exist which can reflect idiosyncratic and sporadic local folkways. Individuals vary widely in their practices and preferences. That said, there are predominant trends and modalities in mobile communication use even as mobile communication practices themselves continue to change. The selections that are made by users to achieve the act of communication are made from many possible modalities. Further, users are often able to choose among myriad affordances that can be designed into the tools and that in turn affect their communication actions and reactions. Hence the evolutionary prism can reveal many subtle and powerful dimensions to communication practices. This is all the more so since mobile communication is quite novel relative to prior location-based technologies of communication, and so thus may more easily reveal to researchers how humans use this new tool to fulfill their various evolutionary heritages. As such, an evolutionary perspective helps us see a fuller picture of the otherwise often mysterious "whys" to the ways mobile communication is used in contemporary society.

\section{References}

1 Bird R, Smith E A, Signaling theory, strategic interaction, and symbolic capital, Current Anthropology, 46, (2005), 221-248, DOI 10.1086/427115.

2 Bleske A L, Buss D M, Opposite sex friendship: Sex differences and similarities in initiation, selection and dissolution, Personality, and Social Psychology Bulletin, 27, (2001), 1310-1323, DOI 10.1177/01461672012710007.

3 Buss D M, Evolutionary psychology: A new paradigm for psychological science, Psychological Inquiry, 6, (1995), 1-30, DOI 10.1207/s15327965pli0601_1.

4 Buss D M, Evolutionary psychology: The new science of the mind, Allyn \& Bacon, 2004. $2^{\text {nd }}$ ed.

5 Buss D M (ed.), The handbook of evolutionary psychology, Wiley, 2005.

6 Buss D M, Schmitt D P, Sexual strategies theory: An evolutionary perspective on human mating, Psychological Review, 100, (1993), 204-232, DOI 10.1037//0033-295X.100.2.204.

7 Byrne R W, Machiavellian intelligence, Evolutionary Anthropology, 5(5), (1996), 172-180, DOI 10.1002/(SICI)1520-6505(1996)5:5<172::AIDEVAN6>3.0.CO;2-H.

8 Campbell S W, Mobile technology and the body: Apparatgeist, fashion, and function, Handbook of Mobile Communication Studies, The MIT Press, 2008. Katz J E, ed.

9 Campbell S W, Perceptions of mobile phone use in public: The roles of individualism, collectivism, and focus of the setting, Communication Reports, 21(2), (2008), 70-81, DOI 10.1080/08934210802301506.

10 Campbell S W, Russo T C, The social construction of mobile telephony: An application of the social influence model to perceptions and uses of mobile phones within personal communication networks, Communication Monographs, 70(4), (2003), 317-334, DOI 10.1080/0363775032000179124.

11 Cartwright J, Evolution and human behavior, The MIT Press, 2000.

12 Castells M, The rise of the network society, Blackwell, 1996.

13 Cotton S R, Anderson W A, Tufekci Z, Old wine in a new technology, or a different type of digital divide?, New Media \& Society, 11, (2009), 11631186, DOI 10.1177/1461444809342056.

14 Cummins D D, Social norms and other minds: The evolutionary roots of higher cognition, The Evolution of Mind (Cummins D D, Allen C, eds.), Oxford University Press, 1998.

15 David K, Cooking, cleaning and charging the cell phone: The impact of cell phone usage on the traditional gender roles of Indian women, Rutgers University, 2007.

16 Dobashi S, The gendered use of keitai in domestic contexts, Personal, Portable, Pedestrian: Mobile Phones in Japanese Life (Ito M, Okabe D, Matsuda M, eds.), MIT Press, 2005.

17 Dunbar R I M, Coevolution of neocortical size, group size and language in humans, Behavioral and Brain Sciences, 16(4), (1993), 681-735, DOI 10.1017/S0140525X00032325.

18 Dunbar R I M, Grooming, gossip, and the evolution of language, Harvard University Press, 1996.

19 Dunbar R I M, The social brain: Mind, language, and society in evolutionary perspective, Annual Review of Anthropology, 32, (2003), 163-181.

20 Dunbar R I M, Gossip in evolutionary perspective, Review of General Psychology, 8(2), (2004), 100-110, DOI 10.1037/1089-2680.8.2.100.

21 Dunbar R I M, Cognitive constraints on the structure and dynamics of social networks, Group Dynamics: Theory, Research and Practice, 12, (2008), 7 16, DOI 10.1037/1089-2699.12.1.7.

22 Dunbar R I M, Duncan N D C, Marriott A, Human conversational behavior, Human Nature, 8, (1997), 231-246, DOI 10.1007/BF02912493.

23 Dunbar R I M, Shultz S, Evolution in the social brain, Science, 317(5843), (2007), 1344-1346, DOI 10.1126/science.1145463.

24 Dunbar R I M, Shultz S, Understanding primate brain evolution, 362(1480), (2007), 649-658, DOI 10.1098/rstb.2006.2001. Philosophical Transactions of the Royal Society of London, Series B, Biological Sciences.

25 Dunbar R I M, Spoors M, Social networks, support cliques and kinship, Human Nature, 6, (1995), 273-290, DOI 10.1007/BF02734142.

26 Ellis B J, The evolution of sexual attraction: Evaluative mechanisms in women, Oxford University Press, 1992. The Adapted Mind: Evolutionary Psychology and the Generation of Culture (Barkow J H, Cosmides L, Tooby J, eds.)

27 Fortunati L, Italy: Stereotypes, true and false (Katz J E, Aakhus M A, eds.), Cambridge University Press, 2002. Perpetual Contact: Mobile Communication, Private Talk, Public Performance.

28 Fortunati L, The mobile phone: Towards new categories and social relations, Information, Communication \& Society, 5(4), (2002), 513-528.

29 Fortunati L, Reflections on mediated gossip, Engagement and Exposure: Mobile Communication and the Ethics of Social Networking (Nyíri K, ed.), Passagen Verlag, 2009.

30 Fox K, Evolution, alienation and gossip. The role of mobile telecommunications in the $21^{\text {st }}$ century, Social Issues Research Center, Oxford, 2001, available at http://www.sirc.org/publik/gossip.shtml

31 Geser H, Towards a sociological theory of the mobile phone, Department of Sociology, Zurich University, 2003, available at http://socio. $\mathrm{ch} / \mathrm{mobile} / \mathrm{t}$ _geser1.htm

32 Geser H, Are girls (even) more addicted? Some gender patterns of cell phone usage, Sociology in Switzerland: Sociology of the Mobile phone, Zürich University, 2006, available at http://socio.ch/mobile/t_geser3.pdf

33 Green N, Outwardly mobile: Young people and mobile technologies, Machines that Become Us: The Social Context of Personal Communication Technology (Katz J E, ed.), Transaction Publishers, 2003.

34 Green E, Singleton C, Mobile selves: Gender, ethnicity and mobile phones in the everyday lives of young Pakistani-British women and men, Information, Communication \& Society, 10(4), (2007), 506-526, DOI 10.1080/13691180701560036.

35 Griskevicius V, Tybur J M, Sundie J M, Cialdini R B, Miller G F, Ken- 
rick D T, Blatant benevolence and conspicuous consumption: When romantic motives elicit strategic costly signals, Journal of Personality and Social Psychology, 93, (2007), 85-102, DOI 10.1037/0022-3514.93.1.85.

36 Haddon L, The social consequences of mobile telephony: Framing questions, Oslo, 2000. Paper presented at the Sosiale Konsekvenser av Mobiltelefoni.

37 Haselton M G, Buss D M, Error management theory: A new perspective on biases in cross-sex mind reading, Journal of Personality and Social Psychology, 78, (2000), 81-91, DOI 10.1037//0022-3514.78.1.81.

38 Haselton M G, Nettle D, The paranoid optimist: an integrated evolutionary model of cognitive biases, Personality and Social Psychology Review, 10, (2006), 47-66, DOI 10.1207/s15327957pspr1001_3.

39 Hill R A, Dunbar R I M, Social network size in humans, Human Nature, 14, (2003), 53-72, DOI 10.1007/s12110-003-1016-y.

40 Igarashi T, Takai J, Yoshida T, Gender differences in social network development, Via mobile phone text messages: A longitudinal study, Journal of Social and Personal Relationships, 22(5), (2005), 691-713, DOI $10.1177 / 0265407505056492$.

41 Johnsen T E, Social context of mobile phone use of Norwegian teens, Machines that Become Us: The Social Context of Personal Communication (Katz J E, ed.), Transaction, 2003.

42 Kamibeppu K, Sugiura H, Impact of the mobile phone on junior highschool students? friendships in the Tokyo metropolitan area, CyberPsychology \& Behavior, 8(2), (2005), 121-130, DOI 10.1089/cpb.2005.8.121.

43 Katz J E, Connections: Social and cultural studies of the telephone in American life, Transaction Publishers, 1999.

44 Katz J E, A nation of ghosts? Choreography of mobile communication in public spaces, Mobile Democracy: Essays on Society, Self and Politics (Nyíri K, ed.), PassagVerlag, 2003.

45 Katz J E, Magic in the air: Mobile communication and the transformation of social life, Transaction Publishers, 2006.

46 Katz J E, Aakhus M, Apparatgeist, Perpetual Contact: Mobile Communication, Private Talk, Public Performance (Katz J E, Aakhus M, eds.), Cambridge University Press, 2002.

47 Katz J E, Rice R E, Acord S, Dasgupta K, David K, Personal mediated communication and the concept of community in theory and practice, Communication Yearbook, 28, (2004), 315-370, DOI 10.1207/s15567419cy2801_9.

48 Katz J E, Sugiyama S, Mobile phones as fashion statements: The cocreation of mobile communication's public meaning, Mobile Communications: Re-negotiation of the Social Sphere (Ling R, Pedersen P, eds.), Springer, 2005.

49 Katz J E, Sugiyama S, Mobile phones as fashion statements: Evidence from student surveys in the U.S. and Japan, New Media \& Society, 8(2), (2006), 321-337.

50 Kirkpatrick L A, Ellis B J, An evolutionary-psychological approach to selfesteem: Multiple domains and multiple functions, The Blackwell Handbook of Social Psychology (Fletcher G, Clark M, eds.), Blackwell, 2001.

51 Kudo H, Dunbar R I M, Neocortex size and social network size in primates, Animal Behaviour, 62, (2001), 711-722, DOI 10.1006/anbe.2001.1808.

52 Lange K, Some concerns about the future of mobile communications in residential markets, Telecommunication: Limits to Deregulation (Christofferson M, ed.), IOS Press, 1993.

53 Leary M R, Tambor E S, Terdal S K, Downs D L, Self-esteem as an interpersonal monitor: The sociometer hypothesis, Journal of Personality and Social Psychology, 68(3), (1995), 518-530, DOI 10.1037//0022-3514.68.3.518.

54 Lemish D, Cohen A A, On the gendered nature of mobile phone culture in Israel, Sex Roles: A Journal of Research, 52(7/8), (2005), 511-521, DOI 10.1007/s11199-005-3717-7.

55 Licoppe C, Connected presence: The emergence of a new repertoire for managing social relationships in a changing communication technoscape,
Environment and Planning D: Society and Space, 22, (2004), 135-156, DOI $10.1068 / \mathrm{d} 323 \mathrm{t}$.

56 Licoppe C, Heurtin J P, Managing one's availability to telephone communication through mobile phones: A French case study of the development dynamics of mobile phone use, Personal and Ubiquitous Computing, 5(2), (2001), 99-108, DOI 10.1007/s007790170013.

57 Licoppe C, Smoreda Z, Are social networks technologically embedded? How networks are changing today with changes in communication technology, Social Networks, 27(4), (2005), 317-335.

58 Lindenfors P, Neocortex evolution in primates: the "social brain" is for females, Biology Letters, 1, (2005), 407-410, DOI 10.1098/rsb1.2005.0362.

59 Ling R, Mobile telephony, mobility, and the coordination of everyday life, Machines that Become Us: The Social Context of Personal Communication (Katz J E, ed.), Transaction, 2003.

60 Ling R, The mobile connection: The cell phone's impact on society, Morgan Kaufmann, 2004.

61 Ling R, Yttri B, Hyper-Coordination via mobile phones in Norway, Perpetual Contact: Mobile Communication, Private Talk, Public Performance (Katz J E, Aakhus M A, eds.), Cambridge University Press, 2002.

62 Liu C M, Donath J S, Urbanhermes: social signaling with electronic fashion, Proceedings of the SIGCHI Conference on Human Factors in Computing Systems, 2006, 885-888.

63 Lycett J E, Dunbar R I M, Mobile phones as lekking devices among human males, Human Nature, 11(1), (2000), 93-104, DOI 10.1007/s12110000-1004-4.

64 Miller G, The mating mind: How sexual choice shaped the evolution of human nature, Doubleday, 2000.

65 Nettle D, Dunbar R, Social markers and the evolution of reciproreciprocal exchange, Current Anthropology, 38, (1997), 93-99.

66 Nyíri K, The mobile telephone as a return to unalienated communication, Knowledge, Technology and Policy, 19(1), (2006), 54-61, DOI 10.1007/s12130-006-1015-5.

67 Palen L, Hughes A, When home base is not a place: parents' use of mobile telephones, Personal and Ubiquitous Computing, 11(5), (2007), 339348, DOI 10.1007/s00779-006-0078-3.

68 Persson A, Intimacy among strangers: On mobile telephone calls in public places, Journal of Mundane Behavior, 2(3), (2001), http://www. mundanebehavior.org/issues/v2n3/persson.htm

69 Peters O, Ben Allouch S, Always connected: a longitudinal field study of mobile communication, Telematics and Informatics, 22(3), (2005), 239-256, DOI 10.1016/j.tele.2004.11.002.

70 Pinker S, Bloom P, Natural language and natural selection, The Adapted Mind (Barkow J H, Cosmides L, Tooby J, eds.), Oxford University Press, 1992.

71 Plant S, On the mobile: The effects of mobile telephones on social and individual life, 2000, available at http://classes.dma.ucla.edu/ Winter03/104/docs/splant.pdf

72 Puro F-P, Finland: A mobile culture, Perpetual Contact: Mobile Communication, Private Talk, Public Performance (Katz J E, Aakhus M, eds.), Cambridge University Press, 2002.

73 Rakow L F, Navarro V, Remote mothering and the parallel shift: women meet the cellular phone, Critical Studies in Mass Communication, 10, (1993), 144-157.

74 Rettie R, Mobile phones as network capital: Facilitating connections, Mobilities, 3(2), (2008), 291-311, DOI 10.1080/17450100802095346.

75 Rheingold R, Smart mobs: the next social revolution, Perseus Publishing, 2003.

76 Ribak R, Remote control, umbilical cord and beyond: The mobile phone as a transitional object, British Journal of Developmental Psychology, 27(1), (2009), 183-196, DOI 10.1348/026151008X388413.

77 Roberts S G M, Dunbar R I M, Pollet T V, Kuppens T, Exploring varia- 
tion in active network size: Constraints and ego characteristics, Social Networks, 31(2), (2009), 138-146, DOI 10.1016/j.socnet.2008.12.002.

78 Saad G T, Applying evolutionary psychology in understanding the Darwinian roots of consumption phenomena, Managerial and Decision Economics, 27(2-3), (2006), 189-201, DOI 10.1002/mde.1292.

79 Sheffield D, Bolton K, Mobile phone use and perceptions of stress, Proceedings of British Psychological Society, Division of Health Psychology Annual Conference, University of Essex, UK, 13-15 September 2006.

80 Skog B, Mobiles and the Norwegian teen: identity, gender and class, Perpetual Contact: Mobile Communication, Private Talk, Public Performance (Katz J E, Aakhus M, eds.), Cambridge University Press, 2002.

81 Symons D, The evolution of human sexuality, Oxford University Press, 1979.

82 Taylor A S, Harper R, The gift of the gab?: A design oriented sociology of young people's use of mobiles, Computer Supported Cooperative Work: The Journal of Collaborative Computing, 12(3), (2003), 267-296.

83 Thurlow C, Brown A, Generation txt? The sociolinguistics of young people's text messaging, Discourse Analysis Online, 1(1), (2003).

84 Tillema T, Schwanen T, Dijst M, Communicating something confidential while travelling by train: the use of a telephone conversation versus silent modes, Transportation, 36(5), (2009), 541-564, DOI 10.1007/s11116-0099212-1.

85 Tooby J, Cosmides L, The psychological foundations of culture, The Adapted Mind: Evolutionary Psychology and the Generation of Culture (Barkow J, Cosmides L, Tooby J, eds.), Oxford University Press, 1992.

86 Tooby J, Cosmides L, Friendship and the banker's paradox: Other pathways to the evolution of adaptations for altruism, Proceedings of the British Academy, Vol. 88, 1996, 119-143.

87 Tooby J, Cosmides L, Conceptual foundations of evolutionary psychology, The Handbook of Evolutionary Psychology (Buss D M, ed.), Wiley, 2005.

88 Turner M, Love S, Howell M, Understanding emotions experienced when using a mobile phone in public: The social usability of mobile (cellular) telephones, Telematics and Informatics, 25, (2008), 201-215, DOI 10.1016/j.tele.2007.03.001.

89 Wei R, Lo V-H, Staying connected while on the move: cell phone use and social connectedness, New Media and Society, 8(1), (2006), 53-72, DOI 10.1177/1461444806059870.

90 Whiten A, Byrne R, Tactical deception in primates, Behavioral and brain sciences, 12, (1988), 233-273, DOI 10.1017/S0140525X00049682.

91 Zahavi A, Mate selection - a selection for handicap, Journal of Theory Biology, 53, (1975), 205-214, DOI 10.1016/0022-5193(75)90111-3.

92 Zahavi A, Reliability in communication systems and the evolution of altruism, Evolutionary Ecology (Stonehouse B, Perrins C M, eds.), Macmillan, London, 1977.

93 Zhou W-X, Sornette D, Hill R A, Dunbar R I M, Discrete hierarchical organization of social group sizes, Proceedings of the Royal Society B, 272, (2005), 439-444, DOI 10.1098/rspb.2004.2970. 